Research Paper

\title{
Microbial control of the invasive spiraling whitefly on cassava with entomopathogenic fungi
}

\author{
Thangavel Boopathi ${ }^{1}$, Palaniappan Karuppuchamy ${ }^{2}$, Soibam B. Singh ${ }^{1}$, \\ Manickavasagam Kalyanasundaram ${ }^{2}$, S. Mohankumar ${ }^{3}$, Madhaiyan Ravi ${ }^{4}$ \\ 1Division of Agricultural Entomology, ICAR Research Complex for NEH Region, Mizoram, India. \\ ${ }^{2}$ Department of Agricultural Entomology, Tamil Nadu Agricultural University, Tamil Nadu, India. \\ ${ }^{3}$ Department of Plant Biotechnology, Tamil Nadu Agricultural University, Tamil Nadu, India. \\ ${ }^{4}$ Krishi Vigyan Kendra, Tamil Nadu Agricultural University, Tamil Nadu, India.
}

Submitted: December 19, 2014; Approved: March 11, 2015.

\begin{abstract}
The entomopathogenic fungi Beauveria bassiana, Metarhizium anisopliae, Lecanicillium lecanii and Isaria fumosorosea were tested for their efficacy in managing the exotic spiraling whitefly Aleurodicus dispersus (Hemiptera, Aleyrodidae) on cassava (Manihot esculenta) during 2 seasons (2011-2012 and 2012-2013). The fungi I. fumosorosea and L. lecanii exhibited promising levels of control ( $>70 \%$ mortality of the $A$. dispersus population). The percent mortality increased over time in both seasons. Application of I. fumosorosea was highly pathogenic to A. dispersus in both seasons compared to the other entomopathogenic fungi. Analysis of the percent mortality in both seasons revealed differences in efficacy between 3 and 15 days after treatment. The season also influenced the effects of the fungi on the $A$. dispersus population. Thus, entomopathogenic fungi have the potential to manage $A$. dispersus infestation of cassava.
\end{abstract}

Key words: Aleurodicus dispersus, Manihot esculenta, biocontrol, entomopathogenic fungi, mortality.

\section{Introduction}

Cassava (M. esculenta Cranrz.) is the most important starchy root crop grown in the tropics (Sánchez et al., 2009) and the main crop cultivated in the Southern Peninsular regions of India. Among the various insect pests of cassava, the exotic spiraling whitefly $A$. dispersus Russell (Hemiptera, Aleyrodidae) can cause losses that reach 53\% (Geetha, 2000). A. dispersus is a polyphagous pest with an extensive host range covering 481 plant species belonging to 295 genera from 90 families of vegetables, fruits and ornamental trees (Srinivasa, 2000; Boopathi and Karuppuchamy, 2013; Boopathi et al., 2012; Boopathi et al., 2014c). Infestation causes premature leaf drop. Moreover, the production of copious amounts of honeydew serves as a substrate for sooty mold growth (Akinlosotu et al., 1993; Boopathi et al., 2013), which in turn reduces the photosynthetic activity and plant vigor (Kumashiro et al.,
1983; John et al., 2007; Boopathi et al., 2014a; Boopathi et al., 2014b). The insect's natural enemies, especially the parasitoids Encarsia guadeloupae Viggiani and Encarsia sp. nr. meritoria Gahan, (Geetha, 2000) and predators, Mallada astur (Banks) and Cybocephalus spp., (Mani and Krishnamoorthy, 1999) have proven to be highly useful in suppressing the spiraling whitefly.

The entomopathogenic fungi have shown good epizootic potential against whiteflies, i.e., Bemisia spp. and Trialeurodes spp., in both field environments and under greenhouse conditions (Fang et al., 1983; Osborne and Landa, 1992; Carruthers et al., 1993; Lacey et al., 1996). I. fumosorosea (Wize) caused the highest mortality to nymphs of the silver leaf whitefly (Bemisia argentifolii Bellows and Perring) under laboratory conditions (Wraight et al., 1998, 2000) and $100 \%$ mortality to A. dispersus nymphs 15 days after treatment (DAT) under laboratory conditions (Boopathi et al., 2013). L. lecanii (Zimmerm.)

Send correspondence to T. Boopathi. Division of Agricultural Entomology, ICAR Research Complex for NEH Region, Mizoram Centre, Kolasib 796081 Mizoram, India. E-mail: boopathiars@gmail.com. 
Zare and Gams produced $80-90 \%$ mortality in $A$. dispersus 15 days after application under in vivo conditions (Aiswariaya et al., 2007) and $97.8 \%$ mortality to $A$. dispersus nymphs 15 DAT under laboratory conditions (Boopathi et al., 2013). The entomopathogenic fungus $B$. bassiana (Balsamo) Vuillemin produced higher mortality to the first instars and adults of the silver leaf whitefly (Nagasi et al., 1998) and 52-98\% mortality to Bemisia at concentrations of 1-4 x $10^{6}$ conidia mL ${ }^{-1}$ (Eyal et al., 1992).

In India, substantial scientific research into crop pest management using entomopathogenic fungi against agricultural and horticultural insect pests began in the early 1990s. Many of the economically important vegetable insect pest species from Hemiptera, Lepidoptera, Coleoptera and Isoptera have been shown to be susceptible to various entomopathogenic fungal isolates (Geetha, 2000; Aiswariaya et al., 2007; Boopathi et al., 2013; Boopathi et al., 2015), including $A$. dispersus. The present study investigated the usefulness of the entomopathogenic fungi $B$. bassiana, M. anisopliae (Metschnikoff) Sorokin, L. lecanii and $I$. fumosorosea as effective biocontrol agents against the most destructive pest of cassava, A. dispersus.

\section{Materials and Methods}

\section{Fungal isolates}

Strains of the entomopathogenic fungi and their sources are listed in Table 1. Isolates were maintained on potato dextrose agar (PDA) in test tubes and stored at $4{ }^{\circ} \mathrm{C}$. Continuous cultures were maintained on slants; subcultures were grown for 14 days at $25^{\circ} \mathrm{C}$ and then stored at $4{ }^{\circ} \mathrm{C}$.

\section{Production and enumeration of spores}

Spore suspensions of each fungal isolate were prepared in $0.5 \%$ aqueous Tween ${ }^{\circledR} 80$ and homogenized with a vortex mixer for two minutes (Lacey, 1997). Then, the spores were counted using a hemocytometer. The conidial suspension was further diluted with $0.5 \%$ aqueous Tween ${ }^{B}$ 80 solution in test tubes to obtain concentrations of $2 \times 10^{9}$ conidia. $\mathrm{mL}^{-1}$.

\section{Spore production}

Air-dried conidia were produced as follows. Maize $(150 \mathrm{~g})$ suspended in $60 \mathrm{~mL}$ of sterile water was autoclaved in polythene bags $(10 \times 25 \mathrm{~cm})$ at $121{ }^{\circ} \mathrm{C}$ and a pressure of $1.05 \mathrm{~kg} \mathrm{~cm}^{-3}$ for $15 \mathrm{~min}$. and cooled to room temperature for $24 \mathrm{~h}$. One milliliter of the $2 \times 10^{9}$ conidia $\mathrm{mL}^{-1}$ suspension was introduced to each polythene bag and incubated for 2 weeks at $26 \pm 3{ }^{\circ} \mathrm{C}$. The two-week-old cultures were harvested, and the air-dried conidia/spores were filtered through a sieve with a particle size of $125 \mu \mathrm{m}$.

\section{Spore harvesting and drying}

The cultures were allowed to air dry overnight in a room with a temperature of $25 \pm 5^{\circ} \mathrm{C}$ and a relative humidity of $50 \pm 5 \%$. Air-dried conidia remained viable and active for up to 8 months without any loss in efficacy for the management of insect pests.

\section{Formulation and application equipment}

A wettable powder formulation was prepared by mixing air-dried conidia with commercial diluent clay (Kaolin, Ashapura Group of Industries, Chennai, Tamil Nadu, India) at a ratio of $1: 4(20 \% \mathrm{w} / \mathrm{w}$ a.i., active ingredient $)$ in a sterile room. All treatments were sprayed using a single-nozzle atomizing (air-assist) sprayer (pneumatic knapsack sprayer). The spray nozzle was carried near ground level for each spray and directed at a right angle to the row. Each row was treated twice, once on each side of the row. The spray volume was $500-700 \mathrm{Lha}^{-1}$. Spraying was performed in the late evening to reduce the possible oppressive effect of solar radiation on conidial/spore germination.

\section{Field evaluation}

Field experiments were conducted in cassava for two seasons at Pollachi, Coimbatore, Tamil Nadu, India, in 2011-2012 (Season 1) and 2012-2013 (Season 2). Rooted sets of cassava (cv. CO-2) were planted in $10 \times 10 \mathrm{~m}$ plots at a spacing of $90 \times 90 \mathrm{~cm}$. Treatments were applied to 5 replicates arranged in a randomized complete block design (RCBD). Weeding, application of manures and fertilizers, and other cultural operations were performed as per crop production guidelines (TNAU, 2012). Furrow irrigation

Table 1 - Details of entomopathogenic fungal isolates.

\begin{tabular}{lccl}
\hline Entomopathogenic fungi & Fungal strains & Host insects & \multicolumn{1}{c}{ Sources } \\
\hline $\begin{array}{l}\text { B. bassiana } \\
\text { M. anisopliae }\end{array}$ & $\mathrm{B}_{2}$ & Helicoverpa armigera & $\begin{array}{l}\text { Department of Plant Pathology, Tamil Nadu Agricultural University } \\
\text { (TNAU), Coimbatore, Tamil Nadu, India }\end{array}$ \\
$\begin{array}{l}\mathrm{M}_{2} \\
\text { L. lecanii }\end{array}$ & Bemisia tabaci & $\begin{array}{l}\text { Department of Plant Pathology, Tamil Nadu Agricultural University } \\
\text { (TNAU), Coimbatore, Tamil Nadu, India }\end{array}$ \\
I. fumosorosea & Bemisia tabaci & $\begin{array}{l}\text { Sun Agro Biotech Research Cen- } \\
\text { tre, Madanantapuram, Porur, Chennai, Tamil Nadu, India } \\
\text { Sun Agro Biotech Research Cen- } \\
\text { tre, Madanantapuram, Porur, Chennai, Tamil Nadu, India }\end{array}$ \\
\hline
\end{tabular}


(approximately 700-800 Lplot $^{-1}$ ) was applied every 2-3 weeks in the absence of rain. The respective wettable powder formulated entomopathogenic fungi were suspended in $1.0 \%$ Teepol $^{\circledR}$ excluding the control. Two applications of fungi were applied 15 days apart due to heavy infestation (>200 A. dispersus per leaf) of A. dispersus (more than the economic threshold level, ETL) at the rate of $2 \times 10^{9}$ conidiamL $L^{-1}$. The first application was applied during the vegetative/reproductive stage of the cassava. The second application was applied to new leaves and shoots that had high populations of newly emerged nymphs and adults of A. dispersus. Both applications were applied to the same plants. Pre-treatment observations of the $A$. dispersus population (no. of nymphs and adults of $A$. dispersus per leaf) were taken $24 \mathrm{~h}$. before each application of fungi, and post-treatment observations were taken at 3, 7, 10 and 15 days after each treatment (DAT). Observations of the $A$. dispersus populations (no. of nymphs and adults of $A$. dispersus per leaf) were recorded on leaves from the top, middle and bottom of 5 tagged plants per plot after the first and second applications.

\section{Data analysis}

Statistical analysis of the data was performed using the methods of Gomez and Gomez (1984) with SAS Software Version 9.3 (SAS Institute Inc., 2011). The data were analyzed using four-way ANOVA. All ANOVA analyses were performed on original values, and the means were separated using the least significant difference (LSD) test at $\mathrm{p}<0.05$ or $\mathrm{p}<0.01$. The percent mortality of $A$. dispersus populations was determined and corrected using the control method of Henderson and Tilton (1955) as follows:

$$
\text { Correct percent reduction }=1-\left[\frac{T_{a}-C_{b}}{T_{b}-C_{a}}\right] \times 100
$$

where $T_{a}=$ number of insects in the treatment after spraying, $T_{b}=$ number of insects in the treatment before spraying, $C_{b}=$ number of insects in the untreated control before spraying and $C_{a}=$ number of insects in the untreated control after spraying.

\section{Results and Discussion}

All entomopathogenic fungal treatments caused medium to high mortality of $A$. dispersus. Individual $A$. dispersus killed by these entomopathogenic fungi dried rapidly on the cassava leaves, and the cadavers remained attached to the cassava leaves. A. dispersus individuals infected by the white muscardine fungus $B$. bassiana were red to red-brown in color. Mycelia and sporulation of entomopathogenic fungi on the cadaver occurred during extended periods of rainfall, higher relative humidity over many nights, or late in the experimental trials. $M$. anisopliae produced green conidia/spores from tightly packed and parallel-oriented conidiogenous cells. The amounts of I. fumosorosea hyphal growth and sporulation were obviously greater 3-5 days after spraying than the other entomopathogenic fungi; however, the postmortem development of the entomopathogenic fungi was not monitored and quantified (Figure 1).

All entomopathogenic fungi caused substantial reductions in A. dispersus populations on cassava following both applications in both seasons. The percent mortality of all entomopathogenic fungi increased over time in both applications and seasons, whereas the highest $A$. dispersus population ( $>180$ per leaf) was observed in the control populations in both seasons 1 and 2 . There were differences between the effects of fungi $(\mathrm{F}=8284.393 ; \mathrm{p}<0.0000)$, applications $(\mathrm{F}=706.327 ; \mathrm{p}<0.0000)$, observation dates $(\mathrm{F}=1489.155 ; \mathrm{p}<0.0000)$, seasons $(\mathrm{F}=40.523$; $\mathrm{p}<0.0000)$ and the interactions on the mortality of $A$. dispersus: fungi $\mathrm{x}$ applications $(\mathrm{F}=47.459 ; \mathrm{p}<0.0000)$, fungi $x$ observation dates $(F=93.773 ; p<0.0000)$, fungi $x$ seasons $(F=8.416 ; p<0.0000)$, applications $x$ observation dates $(\mathrm{F}=19.655 ; \mathrm{p}<0.0000)$, applications $\mathrm{x}$ seasons $(\mathrm{F}=15.256 ; \mathrm{p}<0.0000)$, observation dates $\mathrm{x}$ seasons $(\mathrm{F}=11.249 ; \mathrm{p}<0.0000)$, fungi $\mathrm{x}$ applications $\mathrm{x}$ observation dates $(F=1.998 ; \mathrm{p}<0.0240)$, fungi $x$ observation dates $x$ seasons $(F=2.287 ; p<0.0085)$, applications $x$ observation dates $\mathrm{x}$ seasons $(\mathrm{F}=12.252 ; \mathrm{p}<0.0000)$, and fungi $\mathrm{x}$ applications $\mathrm{x}$ observation dates $\mathrm{x}$ seasons $(\mathrm{F}=3.056$; $\mathrm{p}<0.0004$ ) (Table 2). However, there was not a significant difference between the fungi $\mathrm{x}$ applications $\mathrm{x}$ seasons $(\mathrm{F}=2.329 ; \mathrm{p}<0.0560)$ interaction on the mortality of $A$. dispersus.

The percent mortality resulting from both applications in season 1 demonstrated differences in efficacy between pathogens (Table 3 ). Higher mortality occurred with I. fumosorosea in both application $1(59.04 \%, 100.35 \mathrm{~A}$. dispersus per leaf) and application $2(68.34 \%, 22.55 \mathrm{~A}$. dispersus per leaf) in season 1 than that of the other fungi, whereas in the control treatment, the highest $A$. dispersus populations, 228.30 per leaf and 237.30 per leaf, were observed in season 1 following application 1 and application 2 , respectively. Similarly, in season 2 I. fumosorosea produced higher mortality following both application 1 $(60.70 \%, 80.66 \mathrm{~A}$. dispersus per leaf) and application 2 ( $70.63 \%, 15.55$ A. dispersus per leaf) than that of the other fungi. However, the highest $A$. dispersus population in the control treatment was registered for both application 1 (187.34 per leaf) and application 2 (208.14 per leaf) in season 2. Therefore, the season influenced the effect of the fungi on the reduction of $A$. dispersus. Furthermore, a higher rate of mortality was observed in cassava in season 2 than in season 1 .

The differences in the mortality of $A$. dispersus induced by $B$. bassiana on cassava indicated that there were differences in efficacy between days 3-15 post-treatment (Figure 2a, 2b). B. bassiana produced the highest mortality after application 2 in both seasons. The percent mortality of 


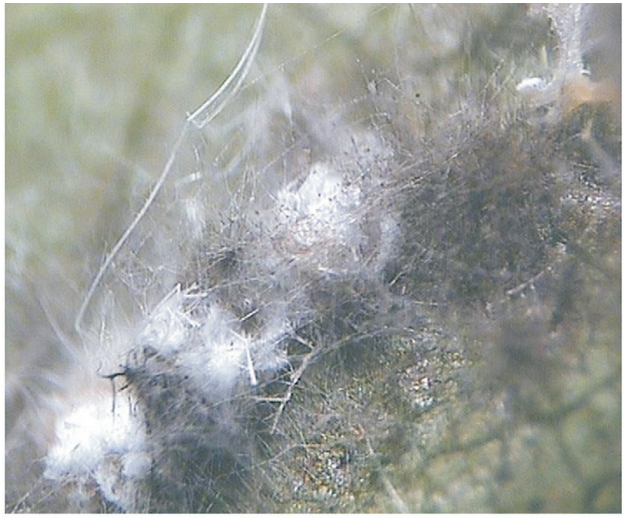

a. I. fumosorosea infected cadaver with spores

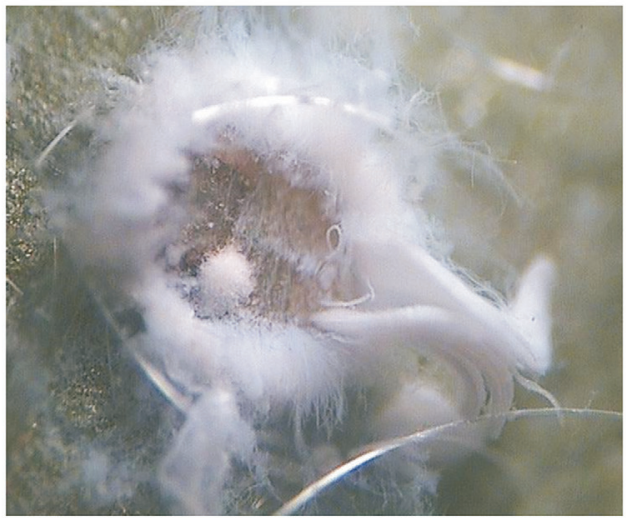

c. B. bassiana infected cadaver with spores

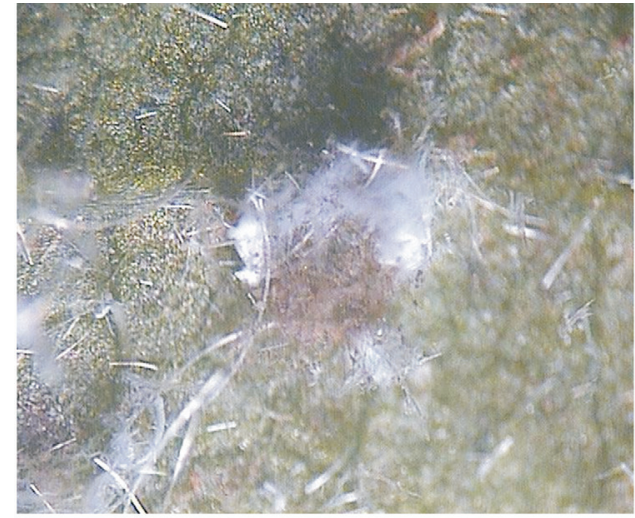

b. L. lecanii infected cadaver with spores

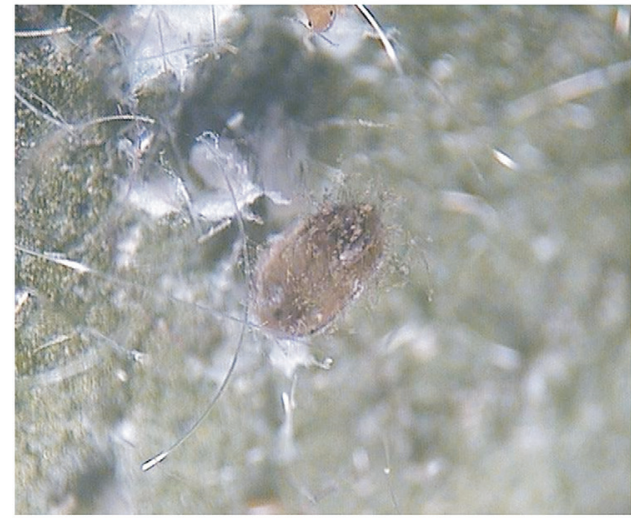

d. M. anisopliae infected cadaver with spores

Figure 1 - Cadavers of $A$. dispersus infected with entomopathogenic fungi.

Table 2 - Analysis of variance (ANOVA) of percent corrected mortality of $A$. dispersus on cassava.

\begin{tabular}{|c|c|c|c|c|}
\hline \multirow[t]{2}{*}{ Source } & \multicolumn{4}{|c|}{$\%$ corrected mortality of $A$. dispersus } \\
\hline & F value & SEd & $\mathrm{CD}(\mathrm{p}=0.01)$ & Probability \\
\hline Fungi (F) & 8284.393 & 0.4065 & 1.0534 & $0.0000 * *$ \\
\hline Application (A) & 706.327 & 0.2571 & 0.6663 & $0.0000 * *$ \\
\hline Day after treatment (D) & 1489.155 & 0.3636 & 0.9422 & $0.0000 * *$ \\
\hline Season $(\mathrm{S})$ & 40.523 & 0.2571 & 0.6663 & $0.0000^{* *}$ \\
\hline \multicolumn{5}{|l|}{ Interaction } \\
\hline $\mathrm{F} \times \mathrm{A}$ & 47.459 & 0.5749 & 1.4898 & $0.0000 * *$ \\
\hline$F \times D$ & 93.773 & 0.8130 & 2.1069 & $0.0000 * *$ \\
\hline $\mathrm{F} \times \mathrm{S}$ & 8.416 & 0.5749 & 1.4898 & $0.0000 * *$ \\
\hline$A \times D$ & 19.655 & 0.5142 & 1.3325 & $0.0000^{* *}$ \\
\hline$A \times S$ & 15.256 & 0.3636 & 0.9422 & $0.0001 * *$ \\
\hline $\mathrm{D} \times \mathrm{S}$ & 11.249 & 0.5142 & 1.3325 & $0.0000^{* *}$ \\
\hline$F \times A \times D$ & 1.998 & 1.1497 & 2.9796 & $0.0240 *$ \\
\hline$F \times A \times S$ & 2.329 & 0.8130 & 2.1069 & $0.0560 \mathrm{~ns}$ \\
\hline$F \times D \times S$ & 2.287 & 1.1497 & 2.9796 & $0.0085^{* *}$ \\
\hline$A \times D \times S$ & 12.252 & 0.7272 & 1.8845 & $0.0000 * *$ \\
\hline$F \times A \times D \times S$ & 3.056 & 1.6260 & 4.2138 & $0.0004 * *$ \\
\hline
\end{tabular}

$\mathrm{ns},{ }^{*}, * *$ non-significant or significant at $\mathrm{p} \leq 0.05$ or $\mathrm{p} \leq 0.01$, ANOVA. 
Table 3 - Percent corrected mortality of $A$. dispersus following both applications on cassava in season 1 and season 2 .

\begin{tabular}{|c|c|c|c|c|c|c|}
\hline Season & $\mathrm{x}$ & Application & $\mathrm{x}$ & Fungi & $\%$ corrected mortality of $A$. dispersus & A. dispersus population per leaf \\
\hline \multirow[t]{10}{*}{1} & & 1 & & Control & $0.00 \mathrm{e}$ & $228.30 \mathrm{e}$ \\
\hline & & & & B. bassiana & $51.14 \mathrm{c}$ & $121.08 \mathrm{c}$ \\
\hline & & & & M. anisopliae & $45.36 \mathrm{~d}$ & $130.40 \mathrm{~d}$ \\
\hline & & & & L. lecanii & $54.43 b$ & $111.98 \mathrm{~b}$ \\
\hline & & & & I. fumosorosea & $59.04 \mathrm{a}$ & $100.35 \mathrm{a}$ \\
\hline & & 2 & & Control & $0.00 \mathrm{e}$ & $237.30 \mathrm{e}$ \\
\hline & & & & B. bassiana & $58.59 \mathrm{c}$ & $36.58 \mathrm{c}$ \\
\hline & & & & M. anisopliae & $50.01 \mathrm{~d}$ & $50.73 \mathrm{~d}$ \\
\hline & & & & L. lecanii & $62.17 b$ & $29.81 b$ \\
\hline & & & & I. fumosorosea & $68.34 \mathrm{a}$ & $22.55 \mathrm{a}$ \\
\hline \multirow[t]{10}{*}{2} & & 1 & & Control & $0.00 \mathrm{e}$ & $187.34 \mathrm{e}$ \\
\hline & & & & B. bassiana & $49.99 \mathrm{c}$ & $101.49 \mathrm{c}$ \\
\hline & & & & M. anisopliae & $47.03 \mathrm{~d}$ & $105.77 \mathrm{~d}$ \\
\hline & & & & L. lecanii & $55.40 \mathrm{~b}$ & $91.38 b$ \\
\hline & & & & I. fumosorosea & $60.70 \mathrm{a}$ & $80.66 \mathrm{a}$ \\
\hline & & 2 & & Control & $0.00 \mathrm{~d}$ & $208.14 d$ \\
\hline & & & & B. bassiana & $59.65 \mathrm{c}$ & $29.53 c$ \\
\hline & & & & M. anisopliae & $56.07 \mathrm{c}$ & $34.51 \mathrm{c}$ \\
\hline & & & & L. lecanii & $65.96 b$ & $21.75 b$ \\
\hline & & & & I. fumosorosea & $70.63 \mathrm{a}$ & $15.55 \mathrm{a}$ \\
\hline
\end{tabular}

Data analyzed with least squares means; means separated using LSD $(\mathrm{p} \leq 0.01)$.

$A$. dispersus induced by $B$. bassiana increased over time when comparing both applications and seasons. The highest mortality was observed at 15 DAT for both application 1 (66.45\%,81.00 A. dispersus per leaf) and application 2 (70.13\%, $24.80 \mathrm{~A}$. dispersus per leaf) in season 1 (Figure $2 \mathrm{a}, 2 \mathrm{~b})$. Similar trends were also observed in season 2, with $68.13 \%$ mortality following application 1 (66.36 A. dispersus per leaf) and 71.95\% mortality following application 2 (19.60 A. dispersus per leaf) (Figure 2b). The lowest mortality was observed 3 DAT for both application 1 (37.90\%, $141.80 \mathrm{~A}$. dispersus per leaf) and application 2 (44.09\%, 44.88 A. dispersus per leaf) in season 1. Similarly, in season 2 the lowest mortality was observed following application $1(34.84 \%, 116.72 \mathrm{~A}$. dispersus per leaf) and application $2(47.07 \%, 34.36 \mathrm{~A}$. dispersus per leaf) at 3 DAT. Weather parameters such as relative humidity, temperature and rainfall were $75-85.0 \%, 22.0-32.3^{\circ} \mathrm{C}$ and 14.0 $\mathrm{mm}$ in season 1 and $72-81 \%, 20.8-31.1{ }^{\circ} \mathrm{C}$ and $9.0 \mathrm{~mm}$ in season 2, respectively. Previously, Eyal et al. (1992) reported that 52-98\% mortality of Bemisia tabaci (Gennadius) was induced by B. bassiana. Wright and Chandler (1992) also reported that B. bassiana caused comparatively lesser mortality than Anthonomus grandis Boheman (boll weevil) in the field. Nagasi et al. (1998) reported that $B$. bassiana produced higher mortality of the first instars and adults of the silver leaf whitefly. Wraight et al. $(1998,2000)$ observed that B. bassiana caused the high- est mortality to nymphs of $B$. argentifolii under laboratory conditions. Furthermore, Wraight and Knaf (1994) used a higher dose of $5 \times 10^{13}$ conidia $\left(2.5\right.$ conidia. $\left.\mathrm{mL}^{-1}\right)$ and achieved $90 \%$ control of $B$. tabaci nymphs 7 DAT, and Boopathi et al. (2013) reported that B. bassiana had a comparatively higher efficacy against $A$. dispersus under laboratory conditions than against $M$. anisopliae.

Metarhizium anisopliae produced the highest mortality following application 2 in both seasons (Figure 2c, 2d). The percent mortality increased over time for both applications and seasons. The highest mortality was observed at 15 DAT following both application $1(59.36 \%, 95.92 A$. dispersus per leaf) and application $2(65.51 \%, 33.72 \mathrm{~A}$. dispersus per leaf) in season 1 (Figure 2c). Similar results were also observed in season 2 , with $65.70 \%$ mortality following application 1 (70.48 A. dispersus per leaf) and $68.71 \%$ mortality following application 2 (23.32 A. dispersus per leaf) (Figure 2d). The next highest mortality rate was observed at $10 \mathrm{DAT}$, whereas the lowest mortality rate was produced at 3 DAT of both application 1 and application 2 in both seasons.

The fungus $L$. lecanii caused a higher mortality to $A$. dispersus following application 2 than following application 1 in both seasons (Figure 3a, 3b). The percent mortality of $A$. dispersus induced by $L$. lecanii increased over time for both applications and seasons. L. lecanii produced the highest mortality at 15 DAT following both application 1 

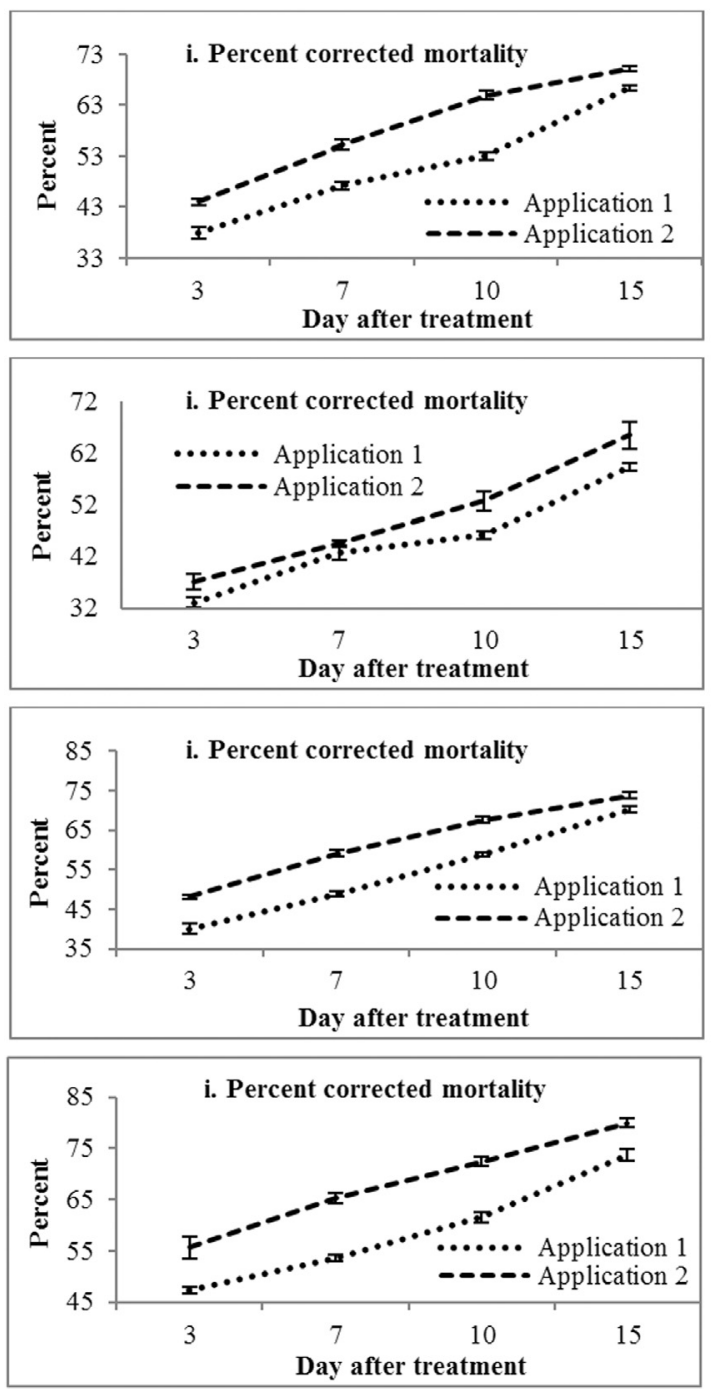
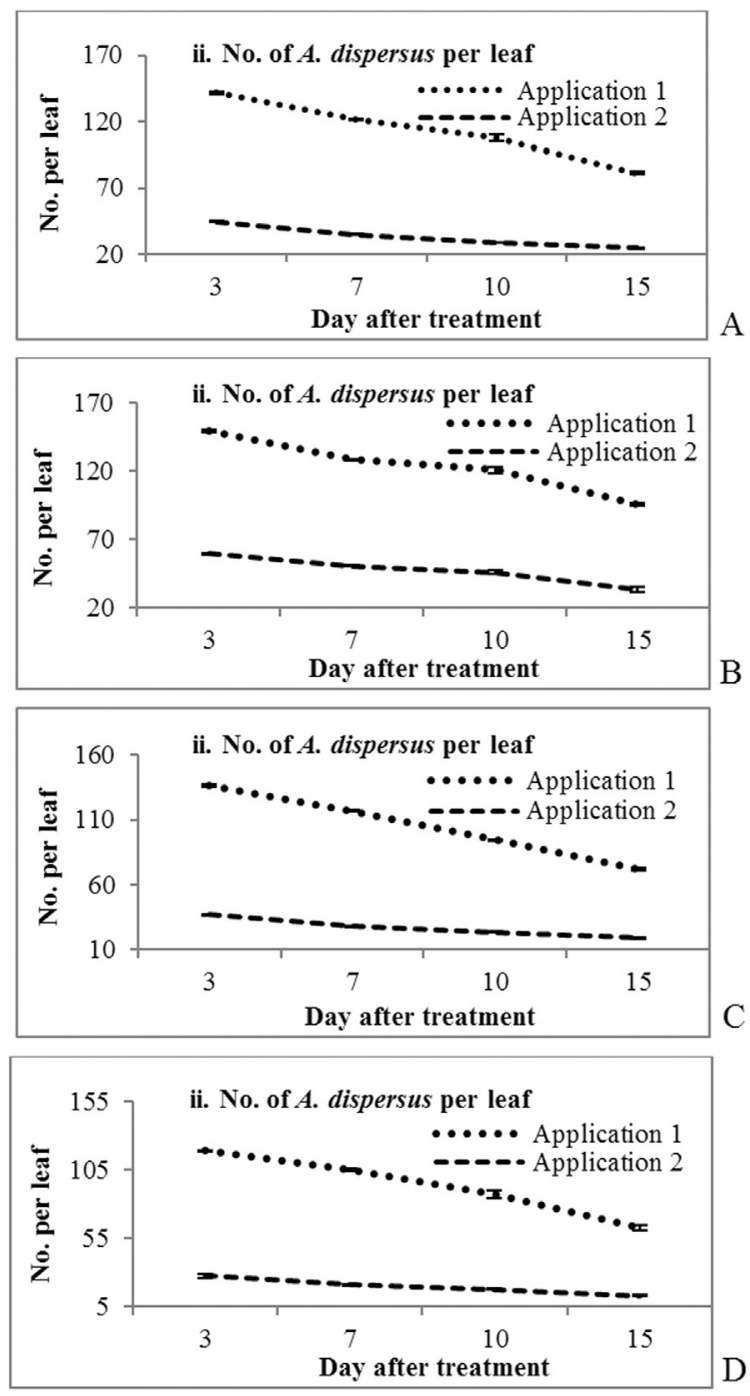

Figure 2 - Efficacy of entomopathogenic fungi on the mortality of $A$. dispersus on cassava in season 1 between 3 and 15 days after treatment (A) $B$. bassiana (B) M. anisopliae (C) L. lecanii (D) I. fumosorosea.

(70.13\%, 71.68 A. dispersus per leaf) and application 2 (73.75\%, 19.24 A. dispersus per leaf) in season 1 (Figure 3a). Similarly, in season 2 L. lecanii caused the highest mortality following application $1(72.94 \%, 56.48 \mathrm{~A}$. dispersus per leaf) and application $2(78.59 \%, 12.76 \mathrm{~A}$. dispersus per leaf) at 15 DAT (Figure $3 \mathrm{~b}$ ). Similar results were reported by Aiswariaya et al. (2007), with $3.6 \times 10^{9}$ spores $\mathrm{mL}^{-1}$ of $L$. lecanii inducing $\sim 90 \%$ mortality of nymphs and $\sim 80 \%$ mortality of adults of $A$. dispersus 15 days after application. However, Boopathi et al. (2013) reported that $L$. lecanii had higher mortality against $A$. dispersus under laboratory conditions.

Isaria fumosorosea produced higher mortality following application 2 than following application 1 in both seasons (Figure 2d). Similar to the other fungi, the percent mortality induced by I. fumosorosea increased over time for both applications and seasons. The highest mortality was due to both application $1(73.70 \%, 62.68 \mathrm{~A}$. dispersus per leaf) and application $2(79.96 \%, 12.80 \mathrm{~A}$. dispersus per leaf) at 15 DAT in season 1 (Figure $3 \mathrm{c}$ ). Similar trends were also observed in season 2 , with $77.73 \%$ mortality following application 1 (45.88 A. dispersus per leaf) and $84.50 \%$ mortality following application 2 (7.48 A. dispersus per leaf) (Figure 3d). The next highest mortality was observed at 10 DAT, whereas the lowest mortality was produced at 3 DAT following both application 1 and application 2 in both seasons. However, the control of the A. dispersus population was the higher in both season 1 ( $>200$ A. dispersus per leaf) (Figure 4) and season 2 (> $150 \mathrm{~A}$. dispersus per leaf) than for any other enthomopathogenic fungi (Figure 4). Similar results were reported by Boopathi et al. (2013), who reported that $2 \times 10^{9}$ conidia $\mathrm{mL}^{-1}$ of I. fumosorosea produced $100 \%$ mortality in A. dispersus 15 DAT under laboratory conditions. This result is in agreement with the present findings. Similarly, Wraight et al. $(1998,2000)$ observed that I. fumosorosea caused higher mortality to nymphs of $B$. 
argentifolii under laboratory conditions, while Ayhan and Kubilay (2005) and Avery et al. (2008) reported that $I$. fumosorosea produced the highest mortality of the greenhouse whitefly Trialeurodes vaporariorum (Westwood).
Temperature and relative humidity are important microclimatic factors that improve the pathogenicity of enthomopathogenic fungi under field conditions. Rainfall (9.0-14.0 $\mathrm{mm})$, relative humidity $(72-85.0 \%)$, and tempera-
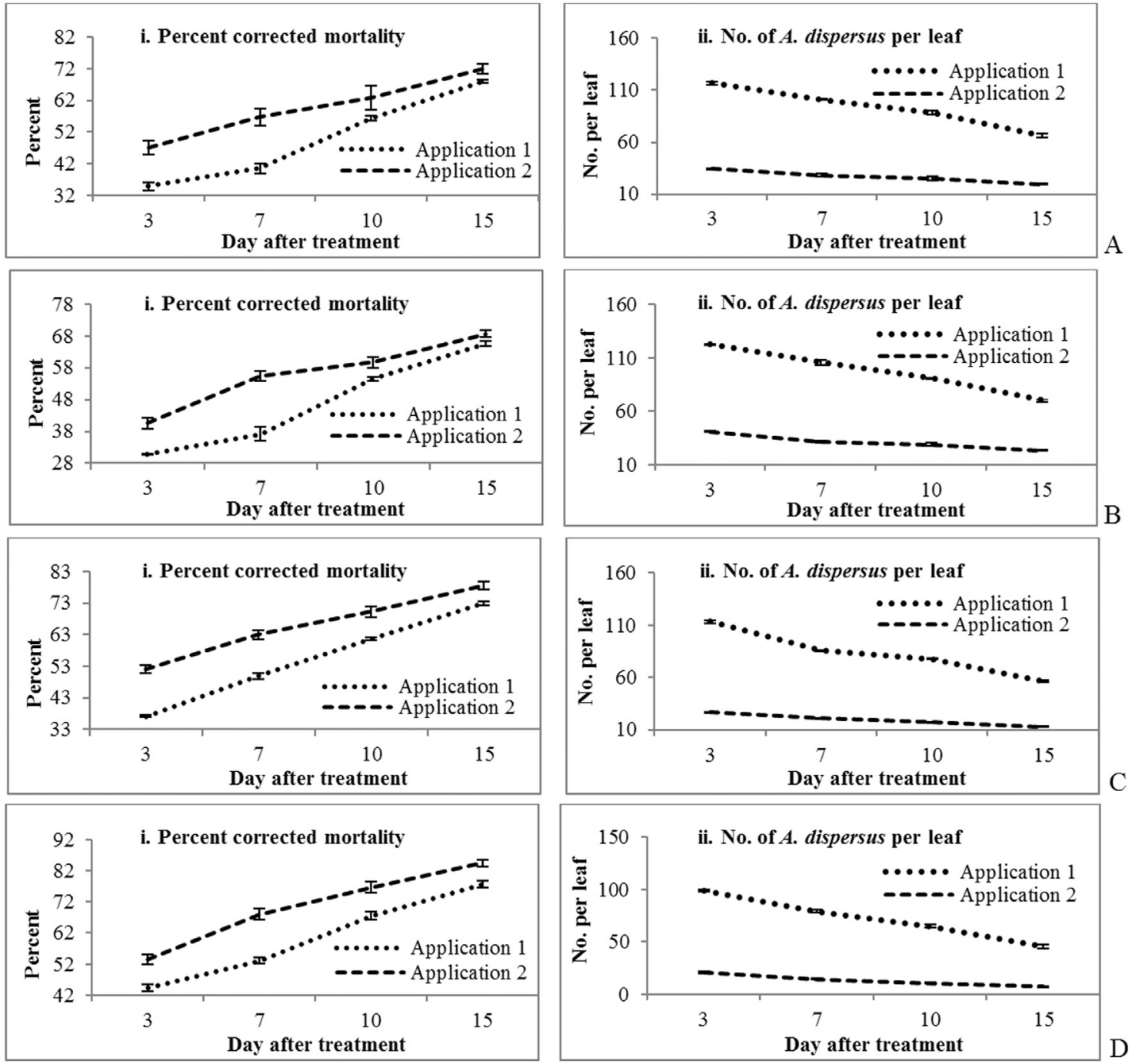

Figure 3 - Efficacy of entomopathogenic fungi on the mortality of $A$. dispersus on cassava in season 2 between 3 and 15 days after treatment (A) $B$. bassiana (B) M. anisopliae (C) L. lecanii (D) I. fumosorosea.
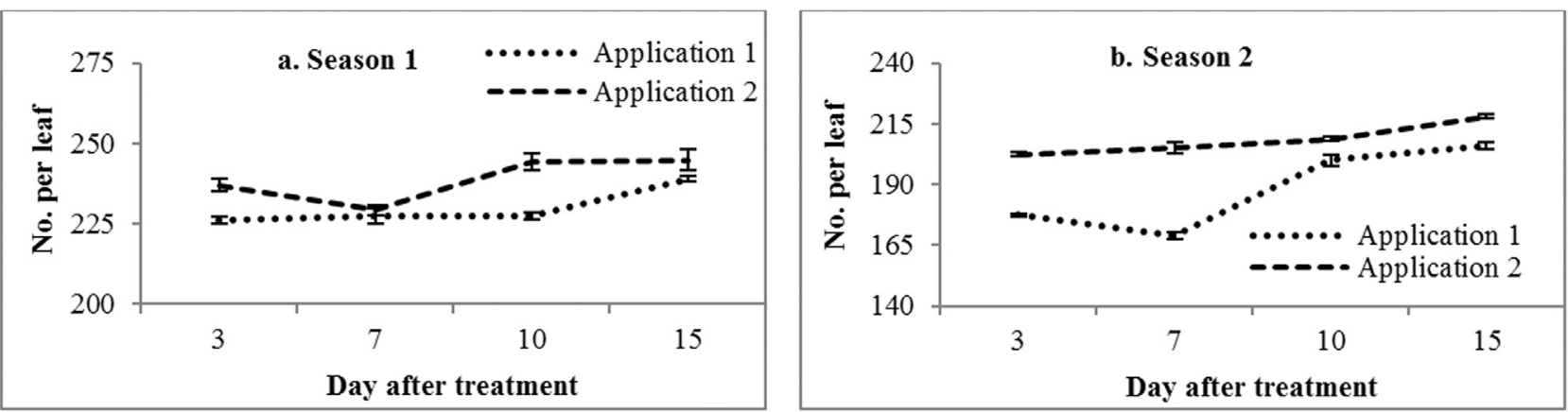

Figure 4 - A. dispersus population (no. per leaf) in control treatment on cassava in both season 1 and season 2 between 3 and 15 days after treatment. 
ture $\left(20.8-32.3{ }^{\circ} \mathrm{C}\right)$ in both season 1 and season 2 favored enthomopathogenic fungal infection and growth. This finding is in agreement with previous studies with $I$. fumosorosea (Boopathi et al., 2013; Boopathi et al., 2015). Our results suggest that I. fumosorosea was more effective in suppressing the exotic $A$. dispersus in the field than in suppressing B. bassiana, M. anisopliae or L. lecanii; this finding is consistent with the lower $\mathrm{LC}_{50}$ value reported for I. fumosorosea in a previously conducted pathogenicity test (Boopathi et al., 2013). M. anisopliae did not produce an added advantage because it could not suppress the rapidly growing A. dispersus population in the field. Thus, effective control of $A$. dispersus was not achieved compared to that of I. fumosorosea. This result could be because $M$. anisopliae was the least effective against $A$. dispersus and contained a lower density of conidia. Similarly, Bateman et al. (1993) reported that M. anisopliae was ineffective against the desert locust at low humidity. Two repeated sprays fifteen days apart were required before $I$. fumosorosea could totally suppress the $A$. dispersus population, indicating that $I$. fumosorosea virulence was maintained throughout the duration of the field experiment.

Among the four enthomopathogenic fungi evaluated, I. fumosorosea and L. lecanii showed promising levels of virulence to $A$. dispersus in both applications and seasons compared to that of M. anisopliae and B. bassiana. Similarly, Boopathi et al. (2015) reported that I. fumosorosea and $L$. lecanii caused the highest mortality to $A$. dispersus on eggplants. Thus, these fungi (I. fumosorosea and $L$. lecanii) can be potentially used as an alternate pest control method to combat the pest insect $A$. dispersus on cassava. Their wide application as mycoinsecticides could be utilized after exploring their pathogenicity in field trials. However, additional testing with yield assessments and economic analyses must be conducted before ultimate conclusions are drawn.

\section{Acknowledgments}

The authors are grateful to the Professor and Head, Department of Agricultural Entomology and the Director, Centre for Plant Protection Studies, Tamil Nadu Agricultural University, Coimbatore, Tamil Nadu, India, for providing the facilities and support. The assistance given by Mr. Muthumariappan, Mr. Mani and Mr. Arulnayagam in recording the observations is acknowledged.

\section{References}

Aiswariaya KK, Manjunatha M, Naik M (2007) Evaluation of fungi Fusarium semitectum Berk and Ravenel and Verticillium lecanii (Zimm.) Viegas against spiraling whitefly Aleurodicus dispersus Russell on guava. Karnataka J Agricul Sci 20:283-287.

Akinlosotu TA, Jackai LEN, Nitonifor NN et al. (1993) Spiralling whitefly, Aleurodicus dispersus in Nigeria. FAO Plant Protec Bull 41:127-129.
Avery PB, Faull J, Simmonds MSJ (2008) Effects of Paecilomyces fumosoroseus and Encarsia formosa on the control of the greenhouse whitefly: preliminary assessment of a compatability study. Bio Control 53:303-316.

Ayhan G, Kubilay M (2005) Pathogenicity of Paecilomyces spp. to the glasshouse whitefly, Trialeurodes vaporariorum, with some observations on the fungal infection process. Turk $\mathrm{J}$ Agric For 29:331-339.

Bateman RP, Carey M, Moore D et al. (1993) The enhance infectivity of Metarhizium flavoviridae in oil formulation to desert locust at low humidities. Ann Appl Biol 122:145-152.

Boopathi T, Karuppuchamy P (2013) Evaluation of ecofriendly agents against spiralling whitefly, Aleurodicus dispersus Russell on brinjal. Madras Agricul J 100:559-661.

Boopathi T, Karuppuchamy P, Kalyanasundaram M et al. (2012) Relative efficacy of botanicals, an organic salt and fish oil rosin soap in controlling the spiralling whitefly, Aleurodicus dispersus Russell on cassava. Hexapoda 19:59-66.

Boopathi T, Karuppuchamy P, Kalyanasundaram M et al. (2013) Pathogenicity, ovicidal action, and median lethal concentrations $\left(\mathrm{LC}_{50}\right)$ of entomopathogenic fungi against exotic spiralling whitefly, Aleurodicus dispersus Russell. J Path 1-7. Available at: http://dx.doi.org/10.1155/2013/393787 Accessed 1 November 2013.

Boopathi T, Karuppuchamy P, Kalyanasundaram M et al. (2014a) Effect of botanicals, fish oil rosin soap and organic salt on eggs of spiralling whitefly, Aleurodicus dispersus. Indian J Plant Protec 42:86-88.

Boopathi T, Karuppuchamy P, Kalyanasundaram M et al. (2014b) Toxicity of newer insecticides against spiralling whitefly, Aleurodicus dispersus under laboratory conditions. Indian J Plant Protec 42:178-180.

Boopathi T, Mohankumar S, Karuppuchamy P et al. (2014c) Genetic evidence for diversity of spiralling whitefly, Aleurodicus dispersus (Hemiptera: Aleyrodidae) populations in India. Fla Entomol 97:1115-1122.

Boopathi T, Karuppuchamy P, Kalyanasundaram M et al. (2015) Microbial control of the exotic spiralling whitefly, Aleurodicus dispersus (Hemiptera: Aleyrodidae) on eggplant using entomopathogenic fungi. Afr J Microbiol Res 9:39-46.

Carruthers RI, Wraight SP, Jones WA (1993) An overview of biological control of the sweetpotato whitefly, Bemisia tabaci. In: D.J. Herber and D.A. Richter (eds) Proceedings Beltwide Cotton Conferences, vol. 2. National Cotton Council of America, Memphis, pp 680-685.

Eyal J, Mabud MDA, Fischdein KL et al. (1992) Assessment of Beauveria bassiana Nov. EO-1 strain, which produce red pigment for microbial control. Appl Biochem Biotechnol 44:65-80.

Fang QX, Gong YX, Zhou YY et al. (1983) Paecilomyces fumosoroseus var. beijingensis. Acta Mycol Sinica 2:168-172.

Geetha B (2000) Biology and Management of Spiralling Whitefly, Aleurodicus dispersus Russell (Homoptera: Aleyrodidae). Ph.D. Dissertation, Tamil Nadu Agricultural University, $105 \mathrm{pp}$.

Gomez KA, Gomez AA (1984) Statistical Procedures for Agricultural Research. John Wiley and Sons, New York.

Henderson CF, Tilton EW (1955) Tests with acaricides against brown wheat mite. J Econ Entomol 48:157-161. 
John B, Darryl H, Greg P (2007) Spiralling whitefly Aleurodicus dispersus exotic threat to Western Australia. Hort Guard TM Initiative AGWEST. Available at: www.agric.wa.gov.au/objtwr/imported_assets/.../pw/.../fs01800.pdf. Accessed May 2007.

Kumashiro BR, Lai PY, Funasaki GY et al. (1983) Efficacy of Nephaspis amnicola and Encarsia haitiensis in controlling Aleurodicus dispersus in Hawaii. Proc Hawaii Entomol Soc 24:261-269.

Lacey L (1997) Manual of Techniques in Insect Pathology. Academic Press, San Diego, 409 pp.

Lacey LA, Fransen JJ, Carruthers RI (1996) Global distribution of naturally occurring fungi of Bemisia, their biologies and use as biological control agents. In: D. Gerling and R.T. Mayer (eds.). Bemisia 1995: Taxonomy, biology, damage, control and management. Intercept Limited, Andover, pp 401-433.

Mani M, Krishnamoorthy A (1999) Development and predatory potential of the green lacewing, Mallada astur (Banks) (Neuroptera: Chrysopidae) on the spiralling whitefly Aleurodicus dispersus Russell (Homoptera: Aleyrodidae). J Biol Cont 13:45-49.

Nagasi A, Paster BL, Brownsbridge M (1998) Screening and bioassay of entomopathogenic fungi for the control of silver leaf whitefly, Bemisia argentifolia. Insect Sci Appl 18:37-44.

Osborne LS, Landa Z (1992) Biological control of whiteflies with entomopathogenic fungi. The Fla Entomol 75:456-471.

Sánchez T, Salcedo E, Ceballos H et al. (2009) Screening of starch quality traits in cassava (Manihot esculenta Crantz). Starch/Stärke 61:12-19.
SAS Institute Inc. (2011) SAS ${ }^{\circledR} 9.3$ System Options: Reference, Second Edition. SAS Institute Inc., SAS Campus Drive, Cary, NC.

Srinivasa MV (2000) Host plants of the spiraling whitefly Aleurodicus dispersus Russell (Hemiptera: Aleyrodidae). Pest Manage Horticul Ecosys 6:79-105.

TNAU (2012) Crop Production Guide - 2005. Chennai and Tamil Nadu Agricultural University, Tamil Nadu.

Wraight JE, Knaf TA (1994) Evaluation of Naturalis-L for control of cotton insects. In: Proceedings Brighton Crop Protection Conference. Pests and diseases, vol. 1. BCPC Publications, Brighton.

Wraight SP, Carruthers RI, Bradley CA et al. (1998) Pathogenicity of the entomopathogenic fungi Paecilomyces spp. and Beauveria bassiana against the silverleaf whitefly, Bemisia argentifolii. J Invert Pathol 71:217-226.

Wraight SP, Carruthers RI, Jaronski ST et al. (2000) Evaluation of the entomopathogenic fungi Beauveria bassiana and Paecilomyces fumosoroseus for microbial control of the silverleaf whitefly, Bemisia argentifolii. Biol Cont 17:203-217.

Wright JE, Chandler LD (1992) Development of a biorational mycoinsecticide: Beauveria bassiana conidial formulation and its application against boll weevil population (Coleoptera: Curculionidae). J Econ Entomol 85:1131-1135.

Associate Editor: André Rodrigues

All the content of the journal, except where otherwise noted, is licensed under a Creative Commons License CC BY-NC. 